\title{
Antibody drug conjugates and bystander killing: is antigen-dependent internalisation required?
}

\author{
Alexander H Staudacher ${ }^{\star 1,2}$ and Michael P Brown ${ }^{1,2,3}$ \\ ${ }^{1}$ Translational Oncology Laboratory, Centre for Cancer Biology, SA Pathology and University of South Australia, Adelaide, SA \\ 5000, Australia; ${ }^{2}$ School of Medicine, University of Adelaide, Adelaide, SA 5000, Australia and ${ }^{3}$ Cancer Clinical Trials Unit, Royal \\ Adelaide Hospital, Adelaide, SA 5000, Australia
}

\begin{abstract}
Antibody drug conjugates (ADCs) employ the exquisite specificity of tumour-specific monoclonal antibodies (mAb) for the targeted delivery of highly potent cytotoxic drugs to the tumour site. The chemistry of the linker, which connects the drug to the $m A b$, determines how and when the drug is released from the mAb. This, as well as the chemistry of the drug, can dictate whether the drug can diffuse into surrounding cells, resulting in 'bystander killing'. Initially, any bystander killing mechanism of action of an $A D C$ was understood to involve an essential sequence of steps beginning with surface antigen targeting, internalisation, intracellular linker cleavage, drug release, and diffusion of drug away from the targeted cell. However, recent studies indicate that, depending on the linker and drug combination, this mechanism may not be essential and ADCs can be cleaved extracellularly or via other mechanisms. In this minireview, we will examine the role of bystander killing by ADCs and explore the emerging evidence of how this can occur independently of internalisation.
\end{abstract}

Ideally, anti-cancer treatments should specifically target and kill tumour cells while leaving normal, healthy tissues relatively unscathed. The therapeutic ratio of the maximum tolerated to the minimally efficacious dose of many of the drugs used in conventional cytotoxic chemotherapy is relatively low, resulting in unwanted side-effects. Nevertheless, these drugs are relatively effective against cancer cells because normal cells have more efficient mechanisms for effluxing cytotoxins, repairing DNA, and clearing dead and damaged cells. Together, these mechanisms limit toxicity even among the rapidly dividing cells of the bone marrow and gastrointestinal epithelium before the next cycle of chemotherapy is given. Immunotherapy has now joined cytotoxic chemotherapy as an effective systemic treatment for cancer, and antibody-based therapy has contributed most significantly to this burgeoning area. Monoclonal antibodies (mAbs) may directly stall or kill tumour cells by binding tumour cell-specific antigens, or indirectly kill tumour cells by inhibiting the immune checkpoint molecules that restrain tumouricidal lymphocytes. Building on these advances, antibody drug conjugate (ADC) therapy has emerged with worldwide marketing approvals for the indications of breast cancer and lymphoma.
An ADC is divided into three distinct parts - the tumourtargeting $\mathrm{mAb}$, the linker, and the cyotoxic drug, also known as the payload or warhead (Figure 1). Modern ADC technology is successful because the exquisite specificity of mAbs is stably coupled with the extreme potency of new cytotoxins. Therapeutic $\mathrm{mAbs}$ are commonly directed at antigens on the surface of tumour cells themselves or the cells or other components of the supporting tumour stroma. Ideally, these antigens are expressed at minimal levels on normal healthy tissues but are highly expressed by tumour cells or within the tumour microenvironment. The payload drugs used with ADCs are orders of magnitude more potent than conventional cytotoxic drugs, such as chemotherapeutic drugs, and as such are too potent to use safely as free drugs for cancer therapy. Moreover, advances in drug/linker chemistries, which enhance plasma stability and control cytotoxin release at the tumour site, have critically enabled modern ADC technology. Consequently, ADCs are expected to have a higher therapeutic ratio than conventional systemic chemotherapy.

Two ADCs are currently FDA-approved for cancer treatment; ado-trastuzumab emtansine (KADCYLA, Roche/Genentech, San Francisco, CA, USA) for the treatment of patients with human 


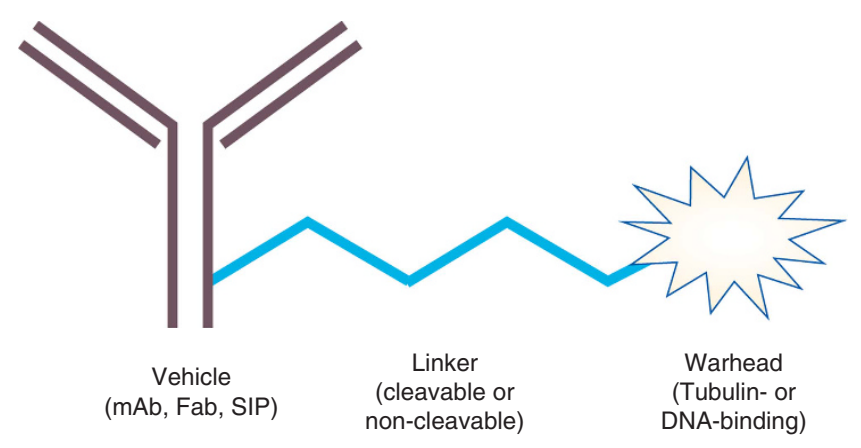

Figure 1. Schematic diagram of antibody drug conjugate. An antibody drug conjugate consists of a cancer-targeting vehicle, usually the whole or fragment of a monoclonal antibody, connected by a cleavable or noncleavable linker to a potent cytotoxic warhead drug. mAb, monoclonal antibody; Fab, fragment antigen binding; SIP, small immune protein.

epidermal growth receptor 2 (HER2)-expressing, metastatic breast cancer (Verma et al, 2012) and brentuximab vedotin (ADCETRIS, Seattle Genetics, Bothell, WA, USA) for the treatment of relapsed or refractory CD30-expressing Hodgkin lymphoma (HL) (Younes et al, 2012) and anaplastic large cell lymphoma (ALCL) (Fanale et al, 2012; Pro et al, 2012). A large number of early phase clinical trials examining the therapeutic effectiveness of a range of different ADCs are currently underway.

Although several recent reviews on ADCs have been published covering the evolution of ADC technology through different mAbs, linker technologies and drug payloads (such as Diamantis and Banerji, 2016; Polakis, 2016; Lambert and Morris, 2017; Beck et al, 2017), information is lacking about the 'bystander killing' that can be mediated by ADCs with particular linker and/or payload combinations and whether internalisation of the ADC is an essential part of its mechanism of action. In this minireview, we will focus primarily on bystander killing by ADCs and the mechanism(s) involved. We will illustrate the potential of ADCmediated bystander killing through the two contrasting clinical examples of ado-trastuzumab emtansine and brentuximab vedotin, and discuss whether direct antigen-mediated internalisation of the $\mathrm{ADC}$ is required for bystander killing.

\section{BYSTANDER KILLING}

Bystander killing occurs when the drug from an ADC is released either from the target cell following internalisation and degradation of the ADC or release of the drug within the extracellular space. In both cases, the drug is then taken up by and kills surrounding or bystander cells, which themselves may or may not express the ADC target antigen. How much an ADC mediates bystander killing depends largely on factors such as the extent of ADC internalisation after binding to the target antigen, the presence of a non-cleavable or cleavable linker, and the hydrophobicity of the attached cytotoxic warhead.

To exert their cytotoxic effects, ADCs such as ado-trastuzumab emtansine, which have a non-cleavable (commonly a thioether) linker, must be internalised by the target cell for the antibody, rather than the linker, to be degraded before release of the drug. This form of ADC does not produce efficient bystander killing because, typically, it contains the potent tubulin-binding maytansine derivative, DM1, and the cleaved drug product cannot enter surrounding cells because its positive charge prevents it from penetrating the cell membrane (Erickson et al, 2006). Therefore, non-cleavable ADCs are primarily effective against the target antigen-expressing cell after internalisation and are best suited to treat cancers that have high and homogenous expression of the target antigen (Kovtun et al, 2006).
Alternatively, ADCs may contain a cleavable linker, which can be cleaved at a defined $\mathrm{pH}$ range or by specific proteases to release the free drug. Although the resulting free drug can directly kill the target cell, it can diffuse out of the target cell to cause bystander killing depending on the drug type and its physicochemical properties (Kovtun et al, 2006; Li et al, 2016; Singh et al, 2016). In spite of a consensus that ADCs are only effective if internalised via a cell-surface antigen, evidence is emerging to indicate that $\mathrm{ADCs}$ with particular linker/drug combinations can exert cell killing through other mechanism(s).

Current FDA-approved ADCs and bystander killing. The FDAapproved ADC, ado-trastuzumab emtansine, comprises the humanised mAb trastuzumab, which targets HER2, an antigen overexpressed in $\approx 25-30 \%$ of breast cancers, with treatment with trastuzumab alone, resulting in partial and complete responses in metastatic breast cancer patients (Cobleigh et al, 1999). The drugconjugated version of trastuzumab, ado-trastuzumab emtansine, consists of trastuzumab bound by a non-cleavable thioether linker to DM1. Once internalised by target cells, the ADC is transported to the endosome where it is degraded, releasing an active but cellimpermeant drug, which kills the targeted cell. The cleaved drug product becomes trapped inside the target cell because it includes a positively charged lysine moiety, which cannot effectively penetrate the cell membrane and cannot therefore elicit bystander killing (Kovtun et al, 2006). This ADC provided significant improvement in progression-free survival when compared with trastuzumab in combination with docetaxel, with fewer adverse incidents reported (Hurvitz et al, 2013). Furthermore, patients with higher than median tumour expression of HER2 mRNA responded better to ado-trastuzumab emtansine than those with lower than median HER2 mRNA expression (Perez et al, 2014), indicating a relationship between the extent of HER2 expression and responsiveness to treatment.

The other FDA-approved ADC uses the chimeric mAb brentuximab to target the CD30 antigen, which is expressed at high density on the malignant Hodgkin and Reed-Sternberg (HRS) cell in HL and on the non-HL cells of ALCL. In contrast, normal tissue expression of CD30 is limited to activated B and T cells (Senter and Sievers, 2012), thymocytes during development, uterine cells during pregnancy, and pancreatic exocrine cells (Ansell, 2014). The ADC, brentuximab vedotin, consists of brentuximab conjugated to the microtubule-binding auristatin, monomethyl auristatin E (MMAE), through a protease-labile, dipeptide valine-citrulline (vc) linker. After binding to CD30, the $\mathrm{ADC}$ is internalised and transported to lysosomes where the linker is cleaved to release the free drug. The clinical results are high rates of durable responses among patients with a number of $\mathrm{CD} 30^{+}$ lymphomas despite great variation in lymphoma cell expression of CD30. Among patients with relapsed or refractory HL (Younes et al, 2012) and ALCL (Pro et al, 2012), the CD30 target antigen is expressed strongly and uniformly on the neoplastic cells. Notwithstanding the strong and uniform CD30 expression on HL and ALCL cells, it was not apparent that a minimal threshold of CD30 was required for tumour response in the pivotal studies of brentuximab vedotin for these lymphomas (Pro et al, 2012, 2013; Younes et al, 2012; Jacobsen et al, 2015). Conversely, in tumours of patients with T-cell lymphomas and diffuse large B-cell lymphoma (DLBCL), CD30 expression is more variable (Bossard et al, 2014; Slack et al, 2014; Jacobsen et al, 2015).

Nevertheless, the $\mathrm{CD} 30^{+}$neoplastic HRS cell of HL represents only a small proportion $(0.1-10 \%)$ of the total lymphoma cell population, which mainly comprises such reactive cell types as $\mathrm{T}$ and B lymphocytes, plasma cells, eosinophils, neutrophils, macrophages, and fibroblasts (Brown and Staudacher, 2014). Hence, unlike ado-trastuzumab emtansine, correlations between tumour CD30 expression and tumour responses to brentuximab vedotin 
have not been found for other lymphomas with variable expression of CD30 (Fromm et al, 2012; Bartlett et al, 2013; Horwitz et al, 2014; Duvic et al, 2015; Jacobsen et al, 2015). In a phase 2 study of 35 patients with $\mathrm{CD} 30^{+}$relapsed or refractory peripheral T-cell lymphoma who received brentuximab vedotin, there was no apparent correlation between response and tumour CD30 expression; 9 of 14 patients $(64 \%)$ had responses with little $(\leqslant 15 \%)$ or no CD30 expression by central review of immunohistochemistry (Horwitz et al, 2014). In another example, an ALCL patient, whose skin lesion had an estimated 3\% occupancy of CD30-binding sites, obtained a complete remission after treatment with brentuximab vedotin (Fromm et al, 2012). Again, in a phase 2 study of 48 patients with $\mathrm{CD} 30^{+}$cutaneous T-cell lymphoma, brentuximab vedotin produced a high overall tumour response rate of $73 \%$ but the responses did not correlate with tumour CD30 expression; even patients with low-level expression $(<10 \%)$ achieved 50\% partial response rate (Duvic et al, 2015).

Finally, there was no statistical correlation between CD30 expression in DLBCL and tumour response to brentuximab vedotin in a phase 2 study, which included 49 relapsed or refractory DLBCL patients, although all the responders had quantifiable CD30 expression by computer assisted digital video analysis immunohistochemistry (cIHC). Remarkably, one patient with relapsed DLBCL, who had 0\% CD30 expression within the tumour biopsy by central review of visual IHC and $1.4 \%$ via cIHC, still achieved a complete response after two cycles of brentuximab vedotin (Jacobsen et al, 2015). In a follow-up study of 52 DLBCL patients with absent CD30 expression by visual IHC, 16 patients (31\%) had an objective response including six complete responses (12\%). Analysis by cIHC showed that 11 of the 16 DLBCL responders had $\geqslant 1 \% \mathrm{CD} 30$, and this was associated with significantly longer median overall survival. These data suggest that a minimum threshold of CD30 expression is required for anti-tumour activity of brentuximab vedotin in DLBCL (Bartlett et al, 2017).

Together, these data suggest that factors other than direct killing of antigen-positive cells by brentuximab vedotin must be involved as even low CD30-expressing disease can be just as responsive to brentuximab vedotin as high CD30-expressing disease. Bystander killing mechanisms may help to explain these observations (Brown and Staudacher, 2014; Masuda et al, 2015). Interestingly, new DNA minor groove binding cytotoxic warheads of picomolar potency, which have been incorporated in ADCs have also been recently reported to exhibit bystander killing effects in pre-clinical models (Flynn et al, 2016; Miller et al, 2016).

Is ADC internalisation required for bystander killing? ADCs with non-cleavable thioether linkers have particular advantages: high stability in serum, manifest anti-tumour activity only after internalisation and lysosomal degradation (Erickson et al, 2006), and greatest anti-tumour efficacy with high and homogenous tumour expression of target antigen (Kovtun et al, 2006). However, these ADCs do not cause bystander killing because only the tumour cells that have internalised the ADC are killed with little or no effect on surrounding, antigen-negative cells (Kovtun et al, 2006).

Cleavable linkers include chemically labile (disulphide and $\mathrm{pH}$ dependent) and enzyme-labile (peptide-based) linkers. It is often presumed that these linkers are cleaved only after internalisation by the target cell with subsequent lysosomal degradation releasing free drug. ADCs with these linkers and appropriate drugs can kill not only the antigen-positive target cells but also the surrounding antigen-negative cells. Consequently, these ADCs are useful for treating tumours with heterogeneous antigen expression (Kovtun et al, 2006; Okeley et al, 2010; Golfier et al, 2014). However, accumulating evidence now suggests that ADC internalisation may not be essential to facilitate tumour cell killing by these particular types of ADC.
pH-dependent linkers. Acid-labile or $\mathrm{pH}$-dependent linkers are designed to be stable at the relatively neutral $\mathrm{pH}$ of blood but are hydrolysed when in an acidic environment $(\mathrm{pH}<5)$. Although degradation of the acid-labile linker in the acidic lysosome is the major degradation pathway for drug release, studies have shown that this may also happen extracellularly. For example, targeting the poorly internalising antigen $\mathrm{CD} 20$ with an ADC consisting of the acid-labile 4-(4-acetylphenoxy)butanoic acid (AcBut) linker and the DNA minor groove-binding drug calicheamicin was effective in a preclinical lymphoma model, whereas substitution with an acid-stable (amide) linker had no anti-tumour effect when compared with the parental antibody alone (Dijoseph et al, 2007). Furthermore, an antibody directed against extracellular rather than cell-surface mucin, which was conjugated via an acid-labile linker (CL2A) to the active metabolite of irinotecan, also showed an effective response in a preclinical pancreatic cancer model (Sharkey et al, 2011). These results suggest that ADCs with an acid-labile linker may not require internalisation for therapeutic potency. The tumour microenvironment, which is much more acidic than normal tissues because of enhanced glycoloysis and lactate generation, may be sufficient for extracellular cleavage of the linker.

Disulphide linkers. Disulphide linkers use a direct covalent bond between sulphide groups belonging to the drug and linker. Two linkers, $N$-succinimidyl-4-(2-pyridyldithio)pentanoate (SPP) and $\mathrm{N}$-succinimidyl-4-(2-pyridyldithio)butanoate (SPDB), which contain one or two methyl groups adjacent to the disulphide bond, respectively, resulting in increasing steric hindrance, have been used for ADCs. The more sterically hindered SPDB linker showed superior activity compared with the SPP linker (Erickson et al, 2010), and in some cases these cleavable linkers result in more potent ADCs than their counterpart non-cleavable linkers (Polson et al, 2009; Erickson et al, 2010). Although ADCs using these linkers can cause bystander killing, it is believed that internalisation, reduction of the disulphide bond, and further modification to the drug within the target cell are required for modifying the potency of the drug once released from the cell to cause bystander killing (Erickson et al, 2006, 2010; Kovtun et al, 2006; Golfier et al, 2014).

However, there are studies that indicate that internalisation of these cleavable linker-based ADCs may not be essential for their anti-tumour activity. For example, conjugation of the tubulinbinding maytansine (DM1) to antibodies targeting poorly internalising antigens (CD20, CD21, CD72) via the cleavable SPP linker were effective in xenograft models and were more effective than ADCs with the same antibody/drug using the non-cleavable thioether linker succinimidyl-4-( $N$-maleimidomethyl)cyclohexane1-carboxylate (SMCC) (Polson et al, 2009). In another example, the ADC targeting the carcinoembryonic antigen cell adhesion molecule 5 (CEACAM5) used a cleavable disulphide linker, which is not internalised or slowly internalising, and was effective in the treatment of colon and pancreatic xenografts (Govindan et al, 2009).

The recent 'traceless' technology uses a direct, unhindered disulphide bond between a drug and an antibody or a small immune protein (SIP). The resulting drug conjugates do not require internalisation by the target cell because the drug is released upon reduction or hydrolysis of the disulphide bond within the tumour microenvironment. This technology has used a SIP format of the F8 antibody, which binds the alternatively spliced extracellular domain A of fibronectin, an extracellular tumour angiogenesis marker. In preclinical studies using (SIP)F8 conjugated to the tubulin-binding drug, cemadotin, which is an analogue of dolastatin and chemically related to the aurostatins, some complete tumour regressions were observed at relatively high daily doses of $43 \mathrm{mg} \mathrm{kg}^{-1}$ given for 5-7 days (Bernardes et al, 
2012; Steiner et al, 2013). Conversely, substitution with a more potent maytansanoid (DM1) resulted in much more durable responses at lower administered doses (Perrino et al, 2014). The mechanism of action of these ADCs depends on a reducing tumour microenvironment to enable cleavage of the disulphide bonds independently of ADC internalisation because the ADC does not become internalised. It is believed that the release of thiols by dead tumour cells may produce a self-amplifying effect, which further increases the degradation of disulphide bonds of the drug conjugate (Bernardes et al, 2012).

More recently, anti-tumour activity of a full-length F8 mAb $\mathrm{ADC}$, which was also conjugated via a direct disulphide bond to the maytansinoid DM1, was observed in a teratocarcinoma xenograft model (Gebleux et al, 2015). Strikingly, although the F8 mAb ADC showed superior tumour uptake compared to the F8 SIP ADC (up to fourfold higher) and much greater stability in plasma, it was less effective in controlling tumour growth compared with F8 SIP ADC (one out of five vs three out of five complete responders) when given at equivalent molar concentrations (Gebleux et al, 2015). In this case, the 'instability' of the SIPdrug interaction may actually result in quicker drug release in the tumour resulting in higher drug accumulation.

Enzyme-labile (peptide-based) linkers. The vc dipeptide linker, which is cleaved preferentially by the lysosomal protease, cathepsin $\mathrm{B}$, is more stable in both human and mouse plasma than the $\mathrm{pH}$ dependent hydrazone linker, resulting in lower toxicity in mice (Doronina et al, 2003). The vc linker has been commonly used to conjugate the tubulin-binding drugs MMAE and monomethyl auristatin F (MMAF) to mAbs. Although structurally similar, MMAE can readily enter cells via passive diffusion whereas MMAF contains a charged carboxylic acid terminus, which limits its passive diffusion into surrounding cells (Doronina et al, 2006). The canonical pathway involved in the intracellular processing of these particular linker/drug combinations first involves internalisation of the $\mathrm{ADC}$, transportation to the lysosome where the linker is degraded by proteases including cathepsin $\mathrm{B}$, resulting in the release of the highly potent, free drug. Then the drug binds to tubulins, and disrupts microtubule assembly to induce cell cycle arrest and ultimately cell death (Figure 2). Although the low cell permeability of MMAF limits its toxicity if the free drug is released from the ADC before the ADC reaches the target cell, MMAFmediated killing is restricted to the target cell because MMAF cannot diffuse out of the cell, and thus cannot cause bystander killing. Consequently, MMAF ADCs require high tumour expression of target antigen to be effective (Smith et al, 2006), but are more potent than vc-MMAE ADCs when targeting internalising antigens in vitro (Sutherland et al, 2006). Conversely, as a free drug, MMAE is much more potent than MMAF (50-200-fold lower $\mathrm{IC}_{50}$ ) because of its increased cell permeability. Consequently, MMAE has the advantage of being able to diffuse out of the target cell and enter surrounding cells to cause bystander killing, something that MMAF cannot do.

These findings were reinforced by a detailed study of MMAEcontaining ADCs, which showed that irrespective of the target antigen and its expression level, the loading ratio of drug on the antibody or the $\mathrm{IC}_{50}$ of the $\mathrm{ADC}$, the concentration of MMAE released from the targeted cell best determined the extent of in vitro tumour cell killing ( $\mathrm{Li}$ et al, 2016). Similarly, the intratumoural concentration of MMAE correlated with in vivo anti-tumour activity of the ADC. Given that these results were not reproduced with a MMAF-containing ADC, the membrane permeability of the released warhead and its ability to diffuse through the tumour seemed to be required for bystander killing.

Although internalisation of vc-MMAE-based ADCs provides one way in which they exert anti-tumour activity, studies indicate that ADC internalisation may not be required for anti-tumour action of these ADCs. For example, targeting the poorly internalised antigen CD21 with an ADC containing vc-MMAF was not effective, whereas conjugation of the same antibody with vc-MMAE showed potent anti-tumour activity in a preclinical lymphoma model (Polson et al, 2009), indicating that mechanisms independent of direct internalisation by antigen binding are at play. Furthermore, targeting of the non-internalising A1 domain of the glycoprotein Tenascin $\mathrm{C}$ with an intact antibody (or a SIP) using the vc linker and MMAE drug combination was effective, with the ADC format capable of producing cures in mice bearing human epidermal carcinoma and glioblastoma tumours (Gebleux et al, 2016). Substitution of a single amino acid of the dipetide linker of this ADC significantly altered the in vivo stability resulting in differences in activity of the ADC, and in some cases different cleaved drug products, whereas substitution with a noncleavable linker abrogated any in vivo anti-cancer activity, confirming that a cleavable linker was essential for any anti-cancer activity of this non-internalising ADC (Dal Corso et al, 2017).

Although not antibody-based, small molecule drug conjugates that use an acetazolamide derivative to bind carbonic anhydrase at the tumour cell surface do not become internalised and are effective in treating renal carcinoma-bearing mice when linked via cathepsin-B cleavable dipeptide linkers to MMAE or the anthracycline analogue, PNU-159682 (Cazzamalli et al, 2016). In this case, the more serum-stable dipeptide linkers (valine-alanine and $\mathrm{vc}$ ) were more active in reducing tumour growth compared with the less-stable valine-lysine or valine-arginine linkers when using the MMAE payload (Cazzamalli et al, 2017).

Factors contributing to ADC-mediated bystander killing of noninternalising ADCs. As discussed above, ADCs employing a cathepsin B cleavable linker can be cleaved independently of direct antigen-internalisation or at least through alternative mechanisms. Cathepsin B expression is not limited to the lysosome, particularly in tumour cells. Tumour cells have increased membrane and secreted levels of cathepsin B, which is an attribute of their invasive phenotype (Poole et al, 1978; Buck et al, 1992; Sloane et al, 2005). Furthermore, tumour associated macrophages and stromal fibroblasts highly express cathepsin B (Campo et al, 1994; Reddy et al, 1995). The overproduction of cathepsin B by tumour cells and tumour-associated cells may at least be partly involved in cleavage of ADCs present in a tumour mass either in extracellular spaces or after target antigen binding (Figure 2). In support of this, conditioned media from tumour cell cultures contain cathepsins, which can cleave an ADC containing a dipeptide linker to release free drug and cause bystander killing (Lam et al, 2014). Furthermore, the cleavage of dipeptide linkers may not be exclusively performed by cathepsin B, as serine hydrolase carboxylesterase 1C can cleave the linker in rodent serum, resulting in ADC instability (Dokter et al, 2014; Dorywalska et al, 2016). Whether other enzymes common to the tumour microenvironment can also cleave dipeptide linkers extracellularly is not known.

The internalisation of ADCs after target antigen binding by tumour-associated myeloid or immune cells may also play a role in ADC catabolism. For example, a specific antibody bound to $\mathrm{CD}{ }^{+}$tumour cells was internalised by macrophages, and macrophage-depletion reduced the anti-tumour efficacy of CD30-directed immunotherapy in vivo (Oflazoglu et al, 2007). Similar results have been seen with CD40-directed immunotherapy, with a combined depletion of NK, neutrophil and macrophages completely abolishing its anti-tumour activity (Oflazoglu et al, 2009). Furthermore, Li et al, 2017 have demonstrated that a non-binding, cleavable ADC was effective as in vivo treatment for human tumour xenografts, which had a significant content of tumour associated macrophages (TAMs). This anti-tumour effect was mediated by the Fc-mediated uptake and processing of the 


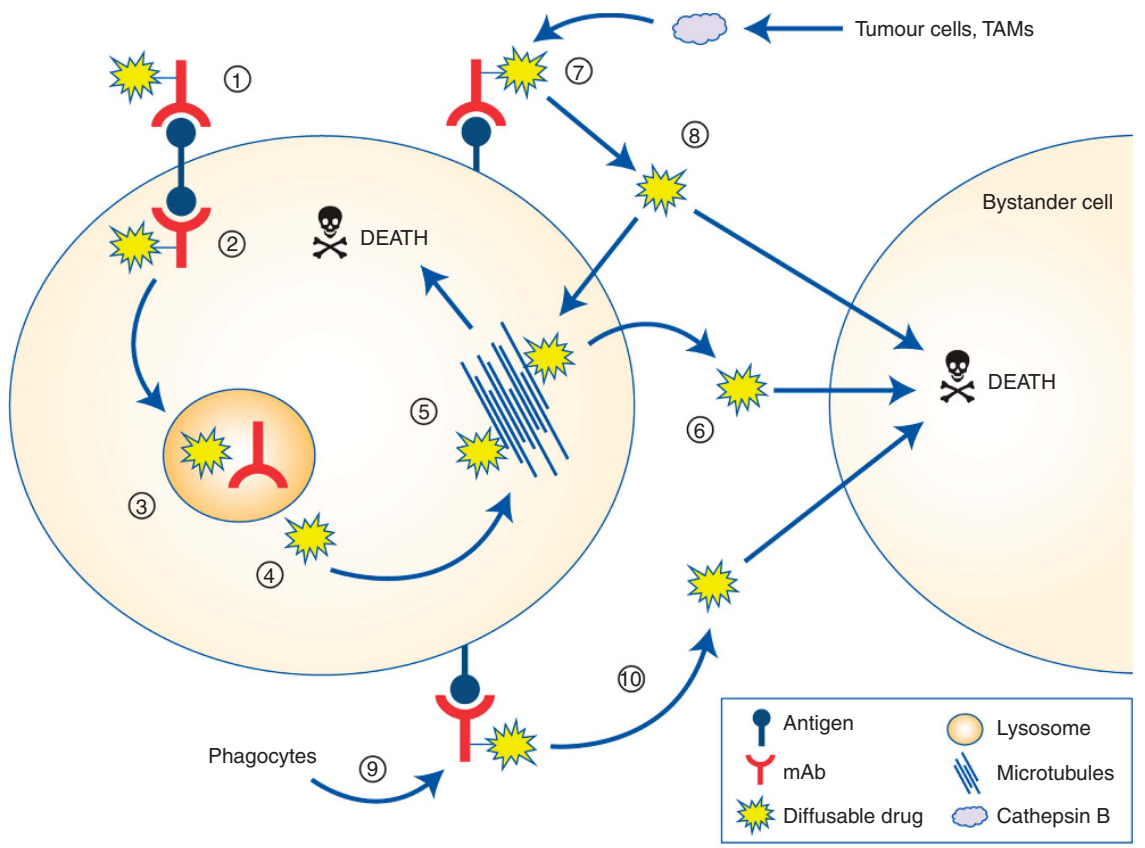

Figure 2. Possible mechanism(s) of action are shown for an ADC with a diffusible drug (MMAE) attached with a cathepsin $B$ cleavable linker. The canonical processing pathway for an ADC involves (1) binding of the ADC to the target antigen and (2) internalisation. (3) The ADC is transported to the lysosome where the linker is cleaved, producing free diffusible drug (4). This free drug can then bind to microtubules (5) or DNA (depending on drug type) within the target cells to induce cell cycle arrest and ultimately result in cell death. The free drug can also diffuse out of the target cell (6) and penetrate surrounding 'bystander' cells to cause cell death. After ADC binding to the target antigen (7) but before internalisation, an alternative route for $A D C$ processing is cleavage by extracellular enzymes (such as cathepsin $B$ ), which are released by surrounding tumour cells and tumour-associated macrophages (TAMs) and which generate diffusible drug from the ADC (8). This free drug can then penetrate surrounding 'bystander' cells resulting in cell death. Also, the ADC-bound target tumour cell may be internalised through Fc-mediated phagocytosis (9), which upon degradation of the target tumour cell would also result in release of free, diffusible drug (10).

ADC by the TAMs, which then resulted in extracellular release of MMAE and bystander tumour cell killing. It is therefore clear that immune cells, in particular macrophages, are required for immunotherapeutic efficacy, and these effects may be dependent on Fc-mediated phagocytosis. However, ADCs with site-directed mutation to reduce Fc-binding still show efficacy, meaning that in some cases Fc-dependent effector functions are not solely required for tumour responses to ADCs (McDonagh et al, 2008).

\section{CONCLUSION}

ADCs are revolutionising the field of cancer treatment by harnessing the specificity of tumour-targeting mAbs with the stability and high potency of advanced linker/drug combinations. Although it has been established that internalisation and intracellular processing of ADCs provide one mechanism of action, it is becoming clear that this is not the only mechanism of ADC action and other processing mechanisms independent of direct cell-surface antigen internalisation can produce effective ADCs.

Depending on the linker type and drug combination, noninternalising $\mathrm{ADCs}$ may have additional advantages by exploiting pathological features inherent to the microenvironment of many tumours such as hypoxia, necrosis, excess reducing equivalents, acidity, an abundance of both active extracellular proteases and protease-rich tumour-infiltrating myeloid cells. By providing the setting for conditional activation of ADCs, tumour properties other than antigen specificity can enhance the tumour selectivity of ADCs. Finally, a strong rationale exists for combining ADCs with other cancer therapies that either act upon or react to elements of the tumour microenvironment. For example, cytotoxic chemotherapy drugs can increase tumour expression of ADC-catabolising cathepsin B (Shree et al, 2011). In addition, tubulin-targeting or DNA-binding warhead drugs consequently released in the tumour microenvironment can be immunostimulatory and thus used to engage the therapeutically beneficial effects of immune checkpoint inhibitors (Muller et al, 2014; Gerber et al, 2016; Rios-Doria et al, 2017).

\section{ACKNOWLEDGEMENTS}

This work was supported in part by the National Health and Medical Research Council (Project Grant ID 1126304), Australia.

\section{CONFLICT OF INTEREST}

The authors declare no conflict of interest.

\section{REFERENCES}

Ansell SM (2014) Brentuximab vedotin. Blood 124(22): 3197-3200.

Bartlett NL, Sharman JP, Oki Y, Advani RH, Bello CM, Winter JN, Yang Y, Kennedy DA, Jacobsen ED (2013) A phase 2 study Of brentuximab vedotin in patients with relapsed or refractory $\mathrm{CD} 30$-positive nonHodgkin lymphomas: interim results in patients with DLBCL and other B-Cell lymphomas. Blood 122(21): 848.

Bartlett NL, Smith MR, Siddiqi T, Advani RH, O'Connor OA, Sharman JP, Feldman T, Savage KJ, Shustov AR, Diefenbach CS, Oki Y, PalancaWessels MC, Uttarwar M, Li M, Yang J, Jacobsen ED (2017) Brentuximab vedotin activity in diffuse large B-cell lymphoma with $\mathrm{CD} 30$ undetectable by visual assessment of conventional immunohistochemistry. Leuk Lymphoma 58(7): 1607-1616. 
Beck A, Goetsch L, Dumontet C, Corvaia N (2017) Strategies and challenges for the next generation of antibody-drug conjugates. Nat Rev Drug Discov 16(5): 315-337.

Bernardes GJ, Casi G, Trussel S, Hartmann I, Schwager K, Scheuermann J, Neri D (2012) A traceless vascular-targeting antibody-drug conjugate for cancer therapy. Angew Chem Int Ed Engl 51(4): 941-944.

Bossard C, Dobay MP, Parrens M, Lamant L, Missiaglia E, Haioun C, Martin A, Fabiani B, Delarue R, Tournilhac O, Delorenzi M, Gaulard P, de Leval L (2014) Immunohistochemistry as a valuable tool to assess CD30 expression in peripheral T-cell lymphomas: high correlation with mRNA levels. Blood 124(19): 2983-2986.

Brown MP, Staudacher AH (2014) Could bystander killing contribute significantly to the antitumor activity of brentuximab vedotin given with standard first-line chemotherapy for Hodgkin lymphoma? Immunotherapy 6(4): 371-375.

Buck MR, Karustis DG, Day NA, Honn KV, Sloane BF (1992) Degradation of extracellular-matrix proteins by human cathepsin B from normal and tumour tissues. Biochem J 282(Pt 1): 273-278.

Campo E, Munoz J, Miquel R, Palacin A, Cardesa A, Sloane BF, Emmert-Buck MR (1994) Cathepsin B expression in colorectal carcinomas correlates with tumor progression and shortened patient survival. Am J Pathol 145(2): 301-309.

Cazzamalli S, Dal Corso A, Neri D (2016) Acetazolamide serves as selective delivery vehicle for dipeptide-linked drugs to renal cell carcinoma. Mol Cancer Ther 15(12): 2926-2935.

Cazzamalli S, Dal Corso A, Neri D (2017) Linker stability influences the antitumor activity of acetazolamide-drug conjugates for the therapy of renal cell carcinoma. J Control Release 246: 39-45.

Cobleigh MA, Vogel CL, Tripathy D, Robert NJ, Scholl S, Fehrenbacher L, Wolter JM, Paton V, Shak S, Lieberman G, Slamon DJ (1999) Multinational study of the efficacy and safety of humanized anti-HER2 monoclonal antibody in women who have HER2-overexpressing metastatic breast cancer that has progressed after chemotherapy for metastatic disease. J Clin Oncol 17(9): 2639-2648.

Dal Corso A, Cazzamalli S, Gebleux R, Mattarella M, Neri D (2017) Proteasecleavable linkers modulate the anticancer activity of noninternalizing antibody-drug conjugates. Bioconjug Chem 28(7): 1826-1833.

Diamantis N, Banerji U (2016) Antibody-drug conjugates-an emerging class of cancer treatment. Br J Cancer 114(4): 362-367.

Dijoseph JF, Dougher MM, Armellino DC, Kalyandrug L, Kunz A, Boghaert ER, Hamann PR, Damle NK (2007) CD20-specific antibodytargeted chemotherapy of non-Hodgkin's B-cell lymphoma using calicheamicin-conjugated rituximab. Cancer Immunol Immunother 56(7): 1107-1117.

Dokter W, Ubink R, van der Lee M, van der Vleuten M, van Achterberg T, Jacobs D, Loosveld E, van den Dobbelsteen D, Egging D, Mattaar E, Groothuis P, Beusker P, Coumans R, Elgersma R, Menge W, Joosten J, Spijker H, Huijbregts T, de Groot V, Eppink M, de Roo G, Verheijden G, Timmers M (2014) Preclinical profile of the HER2-targeting ADC SYD983/SYD985: introduction of a new duocarmycin-based linker-drug platform. Mol Cancer Ther 13(11): 2618-2629.

Doronina SO, Mendelsohn BA, Bovee TD, Cerveny CG, Alley SC, Meyer DL, Oflazoglu E, Toki BE, Sanderson RJ, Zabinski RF, Wahl AF, Senter PD (2006) Enhanced activity of monomethylauristatin F through monoclonal antibody delivery: effects of linker technology on efficacy and toxicity. Bioconjug Chem 17(1): 114-124.

Doronina SO, Toki BE, Torgov MY, Mendelsohn BA, Cerveny CG, Chace DF, DeBlanc RL, Gearing RP, Bovee TD, Siegall CB, Francisco JA, Wahl AF, Meyer DL, Senter PD (2003) Development of potent monoclonal antibody auristatin conjugates for cancer therapy. Nat Biotechnol 21(7): 778-784.

Dorywalska M, Dushin R, Moine L, Farias SE, Zhou D, Navaratnam T, Lui V, Hasa-Moreno A, Casas MG, Tran TT, Delaria K, Liu SH, Foletti D, O’Donnell CJ, Pons J, Shelton DL, Rajpal A, Strop P (2016) Molecular basis of valine-citrulline-PABC linker instability in site-specific ADCs and its mitigation by linker design. Mol Cancer Ther 15(5): 958-970.

Duvic M, Tetzlaff MT, Gangar P, Clos AL, Sui D, Talpur R (2015) Results of a phase II trial of brentuximab vedotin for $\mathrm{CD} 30+$ cutaneous T-cell lymphoma and lymphomatoid papulosis. J Clin Oncol 33(32): 3759-3765.

Erickson HK, Park PU, Widdison WC, Kovtun YV, Garrett LM, Hoffman K, Lutz RJ, Goldmacher VS, Blattler WA (2006) Antibody-maytansinoid conjugates are activated in targeted cancer cells by lysosomal degradation and linker-dependent intracellular processing. Cancer Res 66(8): 4426-4433.
Erickson HK, Widdison WC, Mayo MF, Whiteman K, Audette C, Wilhelm SD, Singh R (2010) Tumor delivery and in vivo processing of disulfide-linked and thioether-linked antibody-maytansinoid conjugates. Bioconjug Chem 21(1): 84-92.

Fanale MA, Forero-Torres A, Rosenblatt JD, Advani RH, Franklin AR, Kennedy DA, Han TH, Sievers EL, Bartlett NL (2012) A phase I weekly dosing study of brentuximab vedotin in patients with relapsed/ refractory CD30-positive hematologic malignancies. Clin Cancer Res 18(1): 248-255.

Flynn MJ, Zammarchi F, Tyrer PC, Akarca AU, Janghra N, Britten CE, Havenith CE, Levy JN, Tiberghien A, Masterson LA, Barry C, D'Hooge F, Marafioti T, Parren PW, Williams DG, Howard PW, van Berkel PH, Hartley JA (2016) ADCT-301, a pyrrolobenzodiazepine (PBD) dimercontaining antibody-drug conjugate (ADC) targeting CD25-expressing hematological malignancies. Mol Cancer Ther 15(11): 2709-2721.

Fromm JR, McEarchern JA, Kennedy D, Thomas A, Shustov AR, Gopal AK (2012) Clinical binding properties, internalization kinetics, and clinicopathologic activity of brentuximab vedotin: an antibody-drug conjugate for CD30-positive lymphoid neoplasms. Clin Lymphoma Myeloma Leuk 12(4): 280-283.

Gebleux R, Stringhini M, Casanova R, Soltermann A, Neri D (2016) Noninternalizing antibody-drug conjugates display potent anti-cancer activity upon proteolytic release of monomethyl auristatin $\mathrm{E}$ in the subendothelial extracellular matrix. Int J Cancer 140(7): 1670-1679.

Gebleux R, Wulhfard S, Casi G, Neri D (2015) Antibody format and drug release rate determine the therapeutic activity of noninternalizing antibody-drug conjugates. Mol Cancer Ther 14(11): 2606-2612.

Gerber HP, Sapra P, Loganzo F, May C (2016) Combining antibody-drug conjugates and immune-mediated cancer therapy: what to expect? Biochem Pharmacol 102: 1-6.

Golfier S, Kopitz C, Kahnert A, Heisler I, Schatz CA, Stelte-Ludwig B, Mayer-Bartschmid A, Unterschemmann K, Bruder S, Linden L, Harrenga A, Hauff P, Scholle FD, Muller-Tiemann B, Kreft B, Ziegelbauer K (2014) Anetumab ravtansine: a novel mesothelin-targeting antibody-drug conjugate cures tumors with heterogeneous target expression favored by bystander effect. Mol Cancer Ther 13(6): 1537-1548.

Govindan SV, Cardillo TM, Moon SJ, Hansen HJ, Goldenberg DM (2009) CEACAM5-targeted therapy of human colonic and pancreatic cancer xenografts with potent labetuzumab-SN-38 immunoconjugates. Clin Cancer Res 15(19): 6052-6061.

Horwitz SM, Advani RH, Bartlett NL, Jacobsen ED, Sharman JP, O'Connor OA, Siddiqi T, Kennedy DA, Oki Y (2014) Objective responses in relapsed $\mathrm{T}$-cell lymphomas with single agent brentuximab vedotin. Blood 123(20): 3095-3100.

Hurvitz SA, Dirix L, Kocsis J, Bianchi GV, Lu J, Vinholes J, Guardino E, Song C, Tong B, Ng V, Chu YW, Perez EA (2013) Phase II randomized study of trastuzumab emtansine versus trastuzumab plus docetaxel in patients with human epidermal growth factor receptor 2-positive metastatic breast cancer. J Clin Oncol 31(9): 1157-1163.

Jacobsen ED, Sharman JP, Oki Y, Advani RH, Winter JN, Bello CM, Spitzer G, Palanca-Wessels MC, Kennedy DA, Levine P, Yang J, Bartlett NL (2015) Brentuximab vedotin demonstrates objective responses in a phase 2 study of relapsed/refractory DLBCL with variable CD30 expression. Blood 125(9): 1394-1402.

Kovtun YV, Audette CA, Ye Y, Xie H, Ruberti MF, Phinney SJ, Leece BA, Chittenden T, Blattler WA, Goldmacher VS (2006) Antibody-drug conjugates designed to eradicate tumors with homogeneous and heterogeneous expression of the target antigen. Cancer Res 66(6): 3214-3221.

Lam M, Lucas J, Maderna A, Wald H, Wojciechowicz M, Dushin R, Peano B, Wang F, Myers J, Tan X, Musto S, Charati M, Gerber H, Loganzo F (2014) Extracellular proteolytic cleavage of peptide-linked antibody-drug conjugates promotes bystander killing of cancer cells. Cancer Res 74(19 Suppl): 4837.

Lambert JM, Morris CQ (2017) Antibody-drug conjugates (ADCs) for personalized treatment of solid tumors: a review. Adv Ther 34(5): 1015-1035.

Li F, Emmerton KK, Jonas M, Zhang X, Miyamoto JB, Setter JR, Nicholas ND, Okeley NM, Lyon RP, Benjamin DR, Law CL (2016) intracellular released payload influences potency and bystander-killing effects of antibody-drug conjugates in preclinical models. Cancer Res 76(9): 2710-2719.

Li F, Ulrich M, Jonas M, Stone IJ, Linares G, Zhang X, Westendorf L, Benjamin DR, Law CL (2017) Tumor-associated macrophages can 
contribute to antitumor activity through fcgammar-mediated processing of antibody-drug conjugates. Mol Cancer Ther 16(7): 1347-1354.

Masuda S, Miyagawa S, Sougawa N, Sawa Y (2015) CD30-targeting immunoconjugates and bystander effects. Nat Rev Clin Oncol 12(4): 245.

McDonagh CF, Kim KM, Turcott E, Brown LL, Westendorf L, Feist T, Sussman D, Stone I, Anderson M, Miyamoto J, Lyon R, Alley SC, Gerber HP, Carter PJ (2008) Engineered anti-CD70 antibody-drug conjugate with increased therapeutic index. Mol Cancer Ther 7(9): 2913-2923.

Miller ML, Fishkin NE, Li W, Whiteman KR, Kovtun Y, Reid EE, Archer KE, Maloney EK, Audette CA, Mayo MF, Wilhelm A, Modafferi HA, Singh R, Pinkas J, Goldmacher V, Lambert JM, Chari RV (2016) A new class of antibody-drug conjugates with potent DNA alkylating activity. Mol Cancer Ther 15(8): 1870-1878.

Muller P, Martin K, Theurich S, Schreiner J, Savic S, Terszowski G, Lardinois D, Heinzelmann-Schwarz VA, Schlaak M, Kvasnicka HM, Spagnoli G, Dirnhofer S, Speiser DE, von Bergwelt-Baildon M, Zippelius A (2014) Microtubule-depolymerizing agents used in antibody-drug conjugates induce antitumor immunity by stimulation of dendritic cells. Cancer Immunol Res 2(8): 741-755.

Oflazoglu E, Stone IJ, Brown L, Gordon KA, van Rooijen N, Jonas M, Law CL, Grewal IS, Gerber HP (2009) Macrophages and Fc-receptor interactions contribute to the antitumour activities of the anti-CD40 antibody SGN-40. Br J Cancer 100(1): 113-117.

Oflazoglu E, Stone IJ, Gordon KA, Grewal IS, van Rooijen N, Law CL, Gerber HP (2007) Macrophages contribute to the antitumor activity of the anti-CD30 antibody SGN-30. Blood 110(13): 4370-4372.

Okeley NM, Miyamoto JB, Zhang X, Sanderson RJ, Benjamin DR, Sievers EL, Senter PD, Alley SC (2010) Intracellular activation of SGN-35, a potent anti-CD30 antibody-drug conjugate. Clin Cancer Res 16(3): 888-897.

Perez EA, Hurvitz SA, Amler LC, Mundt KE, Ng V, Guardino E, Gianni L (2014) Relationship between HER2 expression and efficacy with first-line trastuzumab emtansine compared with trastuzumab plus docetaxel in TDM4450g: a randomized phase II study of patients with previously untreated HER2-positive metastatic breast cancer. Breast Cancer Res 16(3): R50.

Perrino E, Steiner M, Krall N, Bernardes GJ, Pretto F, Casi G, Neri D (2014) Curative properties of non-internalizing antibody-drug conjugates based on maytansinoids. Cancer Res 264: 211-218.

Polakis P (2016) Antibody drug conjugates for cancer therapy. Pharmacol Rev 68(1): 3-19.

Polson AG, Calemine-Fenaux J, Chan P, Chang W, Christensen E, Clark S, de Sauvage FJ, Eaton D, Elkins K, Elliott JM, Frantz G, Fuji RN, Gray A, Harden K, Ingle GS, Kljavin NM, Koeppen H, Nelson C, Prabhu S, Raab H, Ross S, Slaga DS, Stephan JP, Scales SJ, Spencer SD, Vandlen R, Wranik B, Yu SF, Zheng B, Ebens A (2009) Antibody-drug conjugates for the treatment of non-Hodgkin's lymphoma: target and linker-drug selection. Cancer Res 69(6): 2358-2364.

Poole AR, Tiltman KJ, Recklies AD, Stoker TA (1978) Differences in secretion of the proteinase cathepsin B at the edges of human breast carcinomas and fibroadenomas. Nature 273(5663): 545-547.

Pro B, Advani R, Brice P, Bartlett NL, Rosenblatt JD, Illidge T, Matous J, Ramchandren R, Fanale M, Connors JM, Yang Y, Sievers EL, Kennedy DA, Shustov A (2012) Brentuximab vedotin (SGN-35) in patients with relapsed or refractory systemic anaplastic large-cell lymphoma: results of a phase II study. J Clin Oncol 30(18): 2190-2196.

Pro B, Advani RH, Brice P, Bartlett NL, Rosenblatt JD, Illidge T, Matous J, Ramchandren R, Fanale MA, Connors JM, Yang Y, Huebner D, Kennedy DA, Shustov AR (2013) Three-year survival results from an ongoing phase 2 study of brentuximab vedotin in patients with relapsed or refractory systemic anaplastic large cell lymphoma. Blood 122: 1809.
Reddy VY, Zhang QY, Weiss SJ (1995) Pericellular mobilization of the tissuedestructive cysteine proteinases, cathepsins B, L, and S, by human monocyte-derived macrophages. Proc Natl Acad Sci USA 92(9): 3849-3853.

Rios-Doria J, Harper J, Rothstein R, Wetzel L, Chesebrough J, Marrero A, Chen C, Strout P, Mulgrew K, McGlinchey K, Fleming R, Bezabeh B, Meekin J, Stewart D, Kennedy M, Martin P, Buchanan A, Dimasi N, Michelotti E, Hollingsworth R (2017) Antibody-drug conjugates bearing pyrrolobenzodiazepine or tubulysin payloads are immunomodulatory and synergize with multiple immunotherapies. Cancer Res 77(10): 2686-2698.

Senter PD, Sievers EL (2012) The discovery and development of brentuximab vedotin for use in relapsed Hodgkin lymphoma and systemic anaplastic large cell lymphoma. Nat Biotechnol 30(7): 631-637.

Sharkey RM, Karacay H, Govindan SV, Goldenberg DM (2011) Combination radioimmunotherapy and chemoimmunotherapy involving different or the same targets improves therapy of human pancreatic carcinoma xenograft models. Mol Cancer Ther 10(6): 1072-1081.

Shree T, Olson OC, Elie BT, Kester JC, Garfall AL, Simpson K, Bell-McGuinn KM, Zabor EC, Brogi E, Joyce JA (2011) Macrophages and cathepsin proteases blunt chemotherapeutic response in breast cancer. Genes Dev 25(23): 2465-2479.

Singh AP, Sharma S, Shah DK (2016) Quantitative characterization of in vitro bystander effect of antibody-drug conjugates. J Pharmacokinet Pharmacodyn 43(6): 567-582.

Slack GW, Steidl C, Sehn LH, Gascoyne RD (2014) CD30 expression in de novo diffuse large B-cell lymphoma: a population-based study from British Columbia. Br J Haematol 167(5): 608-617.

Sloane BF, Yan S, Podgorski I, Linebaugh BE, Cher ML, Mai J, CavalloMedved D, Sameni M, Dosescu J, Moin K (2005) Cathepsin B and tumor proteolysis: contribution of the tumor microenvironment. Semin Cancer Biol 15(2): 149-157.

Smith LM, Nesterova A, Alley SC, Torgov MY, Carter PJ (2006) Potent cytotoxicity of an auristatin-containing antibody-drug conjugate targeting melanoma cells expressing melanotransferrin/p97. Mol Cancer Ther 5(6): 1474-1482.

Steiner M, Hartmann I, Perrino E, Casi G, Brighton S, Jelesarov I, Bernardes GJ, Pretto F, Neri D (2013) Spacer length shapes drug release and therapeutic efficacy of traceless disulfide-linked ADCs targeting the tumor neovasculature. Chem Sci 4: 297-302.

Sutherland MS, Sanderson RJ, Gordon KA, Andreyka J, Cerveny CG, Yu C, Lewis TS, Meyer DL, Zabinski RF, Doronina SO, Senter PD, Law CL, Wahl AF (2006) Lysosomal trafficking and cysteine protease metabolism confer target-specific cytotoxicity by peptide-linked anti-CD30-auristatin conjugates. J Biol Chem 281(15): 10540-10547.

Verma S, Miles D, Gianni L, Krop IE, Welslau M, Baselga J, Pegram M, Oh DY, Dieras V, Guardino E, Fang L, Lu MW, Olsen S, Blackwell K (2012) Trastuzumab emtansine for HER2-positive advanced breast cancer. N Engl J Med 367(19): 1783-1791.

Younes A, Gopal AK, Smith SE, Ansell SM, Rosenblatt JD, Savage KJ, Ramchandren R, Bartlett NL, Cheson BD, de Vos S, Forero-Torres A, Moskowitz CH, Connors JM, Engert A, Larsen EK, Kennedy DA, Sievers EL, Chen R (2012) Results of a pivotal phase II study of brentuximab vedotin for patients with relapsed or refractory Hodgkin's lymphoma. J Clin Oncol 30(18): 2183-2189.

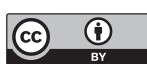

This work is licensed under the Creative Commons Attribution 4.0 International License. To view a copy of this license, visit http://creativecommons.org/licenses/by/4.0/

(C) The Author(s) named above 2017 